\title{
CHAITÉN: UNA HISTORIA EN EL LUGAR
}

\section{ALAN D. BEREZIN B. ${ }^{a}$}

\section{RESUMEN}

La investigación realizada, cuyos resultados se expondrán en el presente artículo, tuvo como objetivo dilucidar las motivaciones y prácticas que llevaron a algunos habitantes de Chaitén a articular un Movimiento Socioterritorial de resistencia por la recuperación y reconstrucción de su pueblo, tras la evacuación obligatoria que debieron hacer del lugar como consecuencia de la erupción volcánica por la que se vieron afectados.

Sustentándose en las teorías de los movimientos sociales, de los espacios territoriales y del sentido de pertenencia se realizó un estudio de tipo exploratorio que permitiera reconstruir la experiencia vivida por los chaiteninos desde mayo de 2008 (mes de la erupción) hasta octubre de 2012.

En cuanto a la estrategia metodológica de la investigación se utilizó la metodología cualitativa a través del análisis de entrevistas en profundidad focalizadas a los principales individuos participantes del movimiento social, y también la recolección de recortes de prensa que relataran los hechos ocurridos.

El componente particular bajo el cual se estudió este movimiento -al no asemejarse a los otros movimientos socioterritoriales de la región- fue el componente cultural que poseen los chaiteninos que lo conformaron, el que se expresa en el fuerte arraigo y pertenencia que sienten por su tierra. Ampliando de esta manera las categorías bajo las cuales pueden estudiarse los nuevos movimientos sociales de carácter territorial.

Tomando en cuenta la alta capacidad de resiliencia de los chaiteninos más su identidad cultural muy ligada al sentimiento de pertenencia es que se puede explicar cómo los chaiteninos "levantaron hoy el pueblo de las cenizas".

PALABRAS CLAVE: movimiento social, espacio territorial, sentido de pertenencia, resiliencia, identidad cultural.

\section{CHAITÉN: A HISTORY IN THE TERRITORY}

\begin{abstract}
The purpose of this investigation was to elucidate the motivation and organizational practices which carried some of Chaitén inhabitants to articulate a resistance Socio-territorial Movement for the reconstruction of the former town, after the mandatory evacuation which they must undertook as a

a Sociólogo, Universidad de Chile. $\$ alanberezinb@gmail.com
\end{abstract}


consequence of the volcanic eruption that took place in the area. With the theory of social-movements, territorial spaces and sense of belonging as framework an exploratory study was conducted in the way it allows to reconstruct the experience lived by the locals from may 2008 to october 2012. Respect the methodological strategies, this researched carried a qualitative approach through focalized indeep interviews to key members of the social-movement as well as press and media extracts about the catastrophe.

A relevant issue that guides this research is the cultural component of the inhabitants of Chaiten -a distinctive aspect of this movement- which took the form of a strong of belonging to the land. This enhance the comprehension of the analysis categories which can be used for new social-movements with territorial demands.

Given the high resilience of the Chaitén people in addition to their cultural identity which is related with the feeling of belonging, one can understand how they "rose the town from the ashes".

KEY WORDS: social-movement, territorial space, feel of belonging, resilience, cultural identity.

\section{INTRODUCCIÓN}

En mayo de 2008 el pueblo de Chaitén se vio afectado por la erupción del volcán Chaitén y como consecuencia de esto se produjo además el desborde del río Blanco (río que cruza el pueblo y lo divide en dos), impactando esto último principalmente la zona sur de la localidad. A partir de esto el Gobierno de Chile, presidido en ese momento por Michelle Bachelet, declara la localidad como zona de catástrofe, evacuando entonces a sus habitantes hacia localidades seguras, como Puerto Montt, Osorno, Chiloé y pueblos alrededores.

Habiendo pasado sólo unas pocas semanas luego de la erupción, algunos de los "Rebeldes de Chaitén" -como solían ser llamados los habitantes tras la catástrofe- comenzaron a sentir descontento con la norma dictada por el Gobierno, la que les impedía regresar a su territorio, es por ello que irán poco a poco utilizando espacios para dar una batalla contra el Gobierno. Su objetivo es que el pueblo se reconstruya en su lugar original de emplazamiento y no en los lugares alternativos que propone el Ejecutivo como soluciones viables.

A partir de agosto de 2008 un grupo de chaiteninos a rehusándose a la idea de no poder estar de forma definitiva en su pueblo, decide no acatar más la norma impuesta por el Gobierno y comienza a pernoctar "ilegalmente" en Chaitén, para así poco a poco ir reconstruyendo su pueblo y las formas de vida que dejaron atrás en este lugar. Tarea que no fue fácil debido a las diversas medidas efectuadas por el Gobierno de Bachelet para desalojar a estos pobladores.
El Ejecutivo a partir de esta misma fecha comienza a buscar soluciones definitivas para el problema de los chaiteninos, como fueron las opciones de reconstruir el pueblo en diversos lugares, entre ellos Villa Santa Lucía, Palena y Santa Bárbara, siendo esta última opción la que toma más peso a partir de febrero de 2009, cuando se decide que finalmente Chaitén será reconstruido en aquel lugar. Sin embargo, los chaiteninos se resisten a la idea de tener que reconstruir sus vidas en un lugar distinto, ya que Chaitén a pesar de lo que decía el Gobierno y la prensa no fue completamente destruido, toda la zona norte del pueblo se encontraba relativamente en buenas condiciones debido a que el río que cruza la ciudad evitó que la lava destruyera todo a su paso. Es por ello, que la reubicación en Santa Bárbara y tener que partir desde cero en esta nueva localidad fue para algunos chaiteninos una idea que, como han demostrado los hechos, no estaban dispuestos a aceptar.

Los pocos habitantes que residian en Chaitén en aquella época comienzan a aunar fuerzas y a organizarse como movimiento para poder reconstruir el pueblo en su lugar original de emplazamiento.

La situación de los "Rebeldes de Chaitén" durante todo el tiempo que dura la problemática (mayo de 2008 hasta abril de 2011) fue bastante precaria, ya que debían ajustar sus vidas a contar con pocos alimentos y a no contar con red de servicios básicos como agua y luz.

El tema de la salud fue complejo también, ya que el hospital que existía no funcionaba y no se 
contaba tampoco con centros médicos cercanos. Para conseguir atención médica, debían viajar a Chiloé en una barcaza que llegaba cada 2 días, o viajar a Palena o Futaleufú que cuentan con centros médicos básicos, pero cuando se presentaba un problema de salud de mayor envergadura, la mejor opción que tenían era ir a Argentina al Hospital de Esquel.

Es recién en febrero de 2011 que el Gobierno de Sebastián Piñera decreta que Chaitén finalmente se reconstruirá en su emplazamiento original, pero sólo la zona norte del pueblo. Sin embargo, los servicios básicos no son repuestos hasta abril de ese mismo año.

En marzo de 2011 podían contarse alrededor de 400 chaiteninos, cerca del $10 \%$ de la población original que hasta antes de la erupción llegaba a los 4.000 habitantes.

\section{Historia e identidad territorial}

La colonización de Chaitén, como indican Villarroel et al. (2005), comienza en la década de 1920 con la llegada de familias provenientes de Chiloé, quienes debido al crecimiento demográfico de la zona buscaban nuevas tierras para cultivar y pastorear que les abrieran mayores posibilidades económicas. Tierras que en aquella época se encontraban bastante aisladas del resto del país, situación que continúa hasta casi finales de la década de los 70, cuando se construye la Carretera Austral.

Estos mismos autores dicen que la identidad actual de los habitantes de este pueblo se basa principalmente en una fuerte memoria colectiva por ser sucesores de pioneros que colonizaron, se asentaron y construyeron comunidad en un territorio que en sus inicios estaba casi completamente desconectado del resto del país. Haber aprendido a sobrevivir a enormes dificultades causadas principalmente por el aislamiento y el convivir con la naturaleza como bosques y el río Yelcho, son las cosas que más los marcan.

Es así como se va construyendo una identidad particular por parte de los chaiteninos:

La mentalidad de sus habitantes estaba sustentada por el valor más importante para ellos: el del ser pionero, la voluntad de los colonos se encontraba sostenida por el principio de estar haciendo patria (Villarroel, 2005, p. 25).

\section{MARCO REFERENCIAL}

\section{Movimientos sociales}

Una definición de movimiento social a la que se adscribió fue la planteada por Diani (1999), quien analiza diversas teorías y extrae una visión en común, definiendo a los Nuevos Movimientos Sociales (NMS) de la siguiente manera:

Un movimiento social es una red de interacción informal entre una pluralidad de individuos, grupos $y / u$ organizaciones, involucrados en un conflicto cultural o politico, sobre la base de una identidad colectiva compartida (Diani, 1999, p. 3).

Otro autor interesante de abordar en cuanto a la construcción de los movimientos sociales es Melucci (1994), quien dice que la noción de identidades colectivas es la clave para entender la gestación de estos movimientos.

Melucci parte hablando de la acción social, la cual según él es:

...el resultado de intenciones, recursos y limites, una orientación intencional construida mediante relaciones sociales desarrolladas en un sistema de oportunidades y obligaciones. (Melucci, 1994, p. 157).

La acción dotada de sentido es lo que permite -según el autor- diferenciar al movimiento social del simple comportamiento colectivo, este último es sólo la suma de intereses individuales en un contexto determinado, mientras que en el movimiento social lo que hay es una identidad colectiva que actúa como base de la acción.

Es la acción colectiva entonces en la que se expresan valores, sentimientos interiorizados y cálculos de interés por parte de sus participantes, la que forma el rasgo identitario de los movimientos sociales hoy en día.

Al mismo tiempo que la acción social se 
va ejecutando, se va fortaleciendo la identidad colectiva de los sujetos que realizan la acción, ya que al realizar una acción en conjunto los individuos van constituyendo un "nosotros" que busca diferenciarse de los "otros". Sin embargo, este nosotros está compuesto de múltiples subjetividades e intereses individuales, los cuales se van consensuando, sólo una vez que se alcanza un acuerdo puede venir la acción.

A partir de esto, se puede decir que la acción social y la identidad colectiva son procesos que se van constituyendo conjuntamente, al devenir conflictos sociales la identidad colectiva del grupo afectado se intensificará y por ende se producirán acciones de movilización, a su vez estas mismas acciones acrecientan el sentimiento de pertenencia de los individuos a este movimiento que están comenzando a construir.

Es posible entonces entender el modo de actuar de algunos chaiteninos como una red de individuos que se organizan ante una problemática determinada, en este caso un conflicto político con el Estado que pretende que los habitantes de Chaitén abandonen su tierra para trasladarlos a un nuevo poblado en el que deben reconstruir sus vidas.

Se puede decir que los habitantes de Chaitén que regresaron sí supieron utilizar los espacios logrando poner su tema en la agenda, de esta manera, hicieron que los políticos modificaran la institucionalidad pudiendo así finalmente recuperar su territorio.

Además se estudiaron cuatro elementos comunes a los Nuevos Movimientos Sociales en Latinoamérica (NMSL).

Según la definición de Svampa (2007), los NMSL presentan las siguientes características:

\section{1.- Anclaje territorial:}

El anclaje territorial hace referencia a cómo el espacio físico, el territorio, es el lugar donde se construyen y adquieren significado las relaciones sociales entre los individuos es a partir de estas relaciones que se dan en un territorio determinado, que se puede hablar que existe una identidad compartida por parte de los individuos que habitan ese espacio.

\section{2.- Acción directa no institucional:}

Esta segunda dimensión plantea como característica generalizada de los movimientos sociales latinoamericanos una forma de lucha basada en la acción directa no institucional y de carácter disruptivo. Esto quiere decir que al no haber canales institucionales para manifestar un descontento y exigir ciertas demandas, los movimientos sociales optan por incurrir en acciones directas organizadas por ellos mismos, que se caracterizan por dar a conocer sus planteamientos a las autoridades y a la gente en general por medio de acciones que logren interrumpir el "status quo".

\section{3.- Democracia directa:}

La democracia directa como forma de articulación de los movimientos sociales latinoamericanos, hoy en día adquiere gran relevancia. Ésta se caracteriza por poseer formas de participación horizontales donde las decisiones de acción colectiva son tomadas directamente por los participantes del movimiento.

\section{4.- Autonomía:}

La cuarta dimensión que caracteriza a los movimientos sociales latinoamericanos de hoy es la demanda por autonomía. Ésta hace referencia no sólo a su forma de organización propia, sino que también se expresa como un planteamiento ideológico que tiene entre sus pilares la autodeterminación como parte fundamental de la forma de construir y llevar a cabo sus proyectos y sus visiones de "mundos alternativos".

Podríamos decir que la conjunción entre identidad territorial, acción directa, difusión de modelos asamblearios y demanda de autonomía, han ido configurando un nuevo ethos militante, esto es, un nuevo conjunto de orientaciones político e ideológicas que configuran la acción colectiva y se expresa a través de nuevos modelos de militancia: militantes sociales $O$ territoriales, militantes socioambientales, activistas culturales, entre otros. (Svampa, 2007, p. 4).

A partir de estas dimensiones características dadas por Svampa de los NMSL se hace evidente 
que el movimiento que se forma en Chaitén presenta al menos la primera dimensión referente al anclaje territorial, ya que su punto de inicio es la lucha por regresar a un territorio, su pueblo, espacio físico donde han construido formas de vida que muchos no están dispuestos a dejar atrás bajo ninguna circunstancia. Es así como el movimiento de resistencia por Chaitén puede ser visto como un movimiento con anclaje territorial, ya que claramente están insertos en él los tres elementos mencionados en la primera dimensión: comunidad, territorio y cultura.

Respecto a si el movimiento constituido por los chaiteninos presenta las otras dimensiones características, no puede ser determinado a priori, es por ello, que el averiguar esto fue parte del trabajo de campo que se realizó para esta investigación.

Como plantea Seoane (2004), han surgido en Latinoamérica una serie de movimientos sociales territoriales, los que se constituyen todos en base a la defensa de un territorio pero bajo diversos caracteres, como pueden ser la mantención de un desarrollo medioambiental que sea sustentable, la mantención de una identidad étnica-cultural o simplemente la lucha por una carencia, como puede ser carencia de techo, trabajo o tierra, entre otros.

A pesar de ello, en la historia de los movimientos sociales latinoamericanos no se hace fácil encontrar experiencias similares a las ocurridas en Chaitén.

Es por esto mismo que se hace necesario agregar otros elementos desde la teoría de los movimientos sociales con carácter territorial que permitan entender de mejor manera hasta qué punto puede verse lo que han hecho los chaiteninos como un movimiento social territorial, para así poder entender sus particularidades $y$ poder estudiarlo de manera más completa. Para esto se tomaron prestados algunos conceptos provenientes de la geografía.

El territorio como espacio geográfico está compuesto por los elementos de la naturaleza por un lado y por las relaciones sociales de los individuos que lo habitan por otro. Las relaciones sociales entonces transforman el espacio en territorio y viceversa. Para Mançano (2005), un territorio es:

Una totalidad restringida por
la intencionalidad que lo creó. Su
existencia así como su destrucción

serán determinadas por las relaciones sociales que dan movimiento al espacio. Así, el territorio es espacio de libertad y dominación, de expropiación y resistencia (Mançano, 2005, p. 4)

Otro autor que abarca el territorio como una característica fundamental de los movimientos sociales es Oslender (2002), quien busca dar a conocer el espacio como un concepto político en el que se articulan relaciones de poder/saber que se dan sobre paisajes materiales y discursivos de dominación y resistencia.

El espacio como objeto de estudio es necesariamente un objeto ideológico o político, ya que a pesar de haber sido formado por elementos naturales e históricos, estos últimos han sido fruto de procesos políticos. Es por ello que cuando se estudia un movimiento social hay que analizar más que sus estructuras y sus objetivos; el análisis del lugar particular del que surge debe ser un elemento primordial en el caso de los movimientos sociales que se construyen sobre la base de una identidad colectiva.

Oslender establece que para estudiar un movimiento social se hace necesario entender primero los lugares donde sus identidades están construidas y articuladas, y conocer además los espacios en los que realizan su acción colectiva.

Es así como se pregunta cuestiones como el grado de influencia que puede haber en la emergencia de un movimiento social de factores como vivir en un lugar determinado y la identidad que se articula detrás de esta experiencia, también se pregunta sobre la influencia de las particularidades del lugar y las historias locales que se dan tras él. Son estos factores, según él, los que ante un conflicto territorial determinado invocan fuertes sentimientos en los habitantes del lugar, sentimientos que pueden constituirse en acciones que lleven a la gestación de un movimiento social que pretende reivindicar un territorio, como lo ocurrido en este caso en Chaitén.

En el caso de movimientos sociales que movilizan alrededor de la defensa de sus territorialidades, por ejemplo, es el espacio material y físico que está al centro de sus actividades. Sin embargo, su lucha 
por la tierra es al mismo tiempo una lucha por el espacio y sus interpretaciones $y$ representaciones (Oslender, 2002, p. 4).

Es a partir de esto, que se llega a la definición de Movimientos Socioterritoriales, son los que buscan constituirse en un territorio que es al mismo tiempo su objetivo y su razón de existir. El territorio es un espacio concreto e inmaterial por el que están dispuestos a luchar.

Los Movimientos Socioterritoriales se caracterizan por construir su espacio intentando conquistar o recuperar una zona geográfica determinada, su conflicto es por el territorio.

Los movimientos socioterritoriales para alcanzar sus objetivos construyen espacios políticos, se espacializan $y$ promueven otro tipo de territorio, de modo que la mayor parte de los movimientos socioterritoriales se forma a partir de los procesos de territorialización $y$ desterritorialización (Mançano, 2005, p. 8).

\section{Pertenencia Socioterritorial}

La geografía cultural dice que el territorio es el espacio de inscripción de la cultura, el cual puede ser un lugar que por diversas razones (políticas, religiosas o culturales) pasa a ser para ciertos grupos o pueblos símbolos que constituyen su identidad.

A partir de esto, se dice que una primera forma de vinculación entre territorio y cultura es la adherencia de esta última a un territorio determinado, lo que constituye una de las formas de objetivación de la cultura, y cuando esto se produce incluso los medios naturales como ríos, montañas y paisajes en general, pasan a ser considerados como parte de los bienes culturales de una región.

Una segunda forma de vinculación entre territorio y cultura sería cuando el territorio es visto como un escenario en que se erigen instituciones y se sitúan prácticas culturales como festividades, ritos, formas lingüísticas y de vestimenta, entre otras. Esto también equivale a una de las formas de objetivación de la cultura.

Una tercera forma de vinculación entre territorio y cultura se da cuando los individuos que lo habitan lo ven como objeto de representación y de apego afectivo, es decir, como símbolo de "pertenencia socioterritorial". Aquí el espacio pasa a formar parte del propio sistema cultural de sus habitantes, lo que implica que en este caso la cultura ya no está siendo objetivada exteriormente como en las dos primeras formas de vinculación, sino que ha pasado a formar parte de la subjetividad de los individuos.

Pollini (1990), otro autor, plantea que las identidades territoriales se definen en primer término como pertenencia socioterritorial, ya que el individuo al formar parte de un grupo que se sitúa en un espacio determinado hará que se tenga una lealtad especial hacia este grupo y hacia el lugar en el que se erige, esto se debe principalmente al hecho de que el individuo a partir de las vivencias que ha tenido en el territorio ha ido poco a poco incorporando simbolismos culturales propios del lugar.

Será entonces a través del estudio de las prácticas de los chaiteninos y del sentido que a éstas le dan, que se podrá comprender qué es lo que representa el pueblo de Chaitén para los habitantes que decidieron regresar tras la erupción. A partir de esto se buscará determinar si esta idea de regresar a como dé lugar al pueblo es producto de una pertenencia socioterritorial fuertemente arraigada en la identidad propia de cada individuo.

\section{Resiliencia}

Otro concepto necesario de abarcar para entender lo ocurrido en Chaitén en términos de cómo sus habitantes lograron organizarse y sobreponerse a la catástrofe, es la resiliencia.

Este concepto ha sido adaptado a las ciencias sociales en especial por la psicología social, entendiéndolo como la capacidad individual y/o comunitaria de desarrollar ante situaciones complejas, pensamientos, conductas y acciones que permitan superar esta adversidad.

La resiliencia es la capacidad que posee un individuo frente a las adversidades, para mantenerse en pie de lucha, con dosis de perseverancia, tenacidad, actitud positiva y acciones, que permiten avanzar en contra de la corriente y superarlas

(Chávez e Yturralde, 1996, citado en Basile 2002, p. 6). 
Para esta investigación se estudió el concepto de resiliencia, pero específicamente en su versión de resiliencia grupal o comunitaria, entendiendo cuáles son los factores que la promueven.

El concepto de resiliencia comunitaria fue desarrollado por Suárez (2001):

Pensar en resiliencia es pensar en los elementos positivos que tenemos todos los seres humanos, aun aquellos que están en las peores condiciones de vida imaginables. Se trata de encontrar los elementos positivos de cada persona para modificar determinada situación y transformarla; implica un concepto dinámico, tanto en lo individual como en lo colectivo. De manera que lo que pensamos que puede ayudar a alguien a superar una enfermedad, puede aplicarse también a organizaciones sociales más complejas. Entramos aquí en terreno de lo que denominamos resiliencia comunitaria (Suárez, 2001, citado en Basile, 2002, p. 7).

Adentrándonos en el tema de la resiliencia para el caso más específico de Chaitén, se hace necesario explicitar el concepto de resiliencia comunitaria ante desastres naturales:

La resiliencia, en relación con los desastres, es el esfuerzo natural de un sistema para resistir embates y resurgir rápidamente tras el impacto o los efectos de un fenómeno natural. Es un asunto de capacidades colectivas, armonizadas en torno a un plan para hacer frente a condiciones críticas. Implica la habilidad de ser flexible (Torres, 2011, p. 27).

Suárez parte sus estudios desde la observación de que en cada catástrofe o desastre que ocurre en una comunidad determinada se produce un efecto movilizador -como él le llama-, el cual les permite a los individuos que la conforman, a pesar del dolor y la pérdida de recursos, el sobreponerse y continuar adelante. De esta manera es como estos mismos individuos afectados logran reparar los daños ocurridos para así comenzar a reconstruir sus vidas. A partir de esto, el autor, plantea los principales Factores potenciadores de la resiliencia comunitaria:

- $\quad$ Autoestima Colectiva: Sentimiento de pertenencia y orgullo por un grupo en particular, es el reconocerse y sentirse identificado con una comunidad $y$ /o localidad.

Para Suárez el que un grupo posea alta autoestima es un factor que influye directamente en su capacidad de reconstruirse.

- Identidad Cultural: Son las costumbres, valores, normas y formas de ser que comparten los individuos que forman parte de una comunidad, y que buscan mantenerse a lo largo del tiempo a pesar de las transformaciones que van ocurriendo. Es en definitiva la persistencia del ser social más allá de la catástrofe.

- Actitud Democrática: Capacidad de elegir líderes auténticos y verdaderamente representativos, así como también de tomar decisiones de una manera efectivamente democrática.

Afirmar definitivamente si Chaitén como comunidad es realmente tan resiliente como parece, sólo se hará a partir de la exposición de los resultados de esta investigación, dando a conocer los factores de resiliencia comunitaria que poseen los chaiteninos.

\section{METODOLOGÍA}

Para este estudio de tipo exploratorio, se desarrolló una metodología cualitativa para abordar el problema de investigación.

La metodología cualitativa se caracteriza por buscar captar la subjetividad de los individuos, comprender la realidad social desde la mirada particular que poseen de ella los sujetos.

Se utilizó como técnica la Entrevista en Profundidad Focalizada, la que se caracteriza por buscar obtener el punto de vista de sujetos que se han visto envueltos en situaciones particulares, que no han sido controladas pero que de alguna manera han sido observadas. Estas entrevistas fueron individuales y con preguntas abiertas semi-estructuradas a informantes claves del proceso ocurrido. 
A partir de esto entonces, se realizaron Entrevistas en Profundidad Focalizadas a actores claves de la experiencia vivida en Chaitén, para de esta manera recolectar datos útiles que permitieran estudiar y dar a conocer más información sobre los acontecimientos, situaciones y personas que hicieron parte de este proceso y de cuáles eran sus miradas al respecto.

Las entrevistas se realizaron en el mismo pueblo de Chaitén durante enero y febrero de 2011.

Se partió con una entrevista a un informante clave, quien fue contactado en un primer momento, para luego, a partir de él, contactar a otros chaiteninos que aportaran información relevante acerca del tema de estudio, y así sucesivamente. $\mathrm{O}$ sea a través de los contactos que formaban parte de la red de los mismos entrevistados se fueron contactando individuos que fueran útiles para la investigación; esto se conoce con el nombre de efecto "bola de nieve".

La población muestral, no tuvo en este caso un número definido de antemano debido a su carácter cualitativo, por lo que fue una muestra opinática, es decir, que no tiene representatividad probabilística. En razón de ello, el tipo de muestreo elegido fue el de criterio, en el cual se propone la selección de todos los casos que concuerden con algún criterio, asegurando calidad (Di Silvestre, 1999). Los criterios para la selección de los sujetos pertinentes para integrar la muestra fue que fuesen habitantes del pueblo de Chaitén en el momento en que se llevó a cabo el trabajo de campo, que hubiesen retornado al pueblo de manera definitiva tras la erupción en el mismo año en que esta ocurrió y que, por último, hubieran sido partícipes de alguna organización y acción desarrollada por el movimiento social conformado por los chaiteninos. Para que de esta manera fuesen capaces de dar una mirada amplia de cómo ha sido toda la experiencia.

Para la selección de los casos muestrales, se trabajó con aquellas personas que accedieron voluntariamente a ser parte del estudio previa presentación del tema de investigación. El tamaño de la muestra se determinó según el criterio de saturación y las necesidades de información para responder a los objetivos del estudio, la selección del número de entrevistados llegó hasta el punto en que se produjo la saturación teórica, es decir, cuando se consideró que nuevas entrevistas no aportarían nuevos datos, producto de la continua repetición de los existentes, por lo que se carecía de novedad.

Para obtener la información requerida para el estudio se construyeron dos instrumentos que permitieran captar el discurso de los participantes del movimiento social. El primero de éstos, dirigido a habitantes del pueblo de Chaitén que hayan sido de los primeros en retornar al pueblo, preguntándoles principalmente cómo fue el proceso de articulación del movimiento social, qué tipo de acciones llevaron a cabo, cómo fue el proceso de reconstrucción del pueblo y mediante qué prácticas se hizo esto posible, así como también se buscó entender qué es lo que motivó a algunos chaiteninos a volver y dar esta lucha por recuperar su lugar.

El segundo tipo de entrevista está dirigida específicamente a un individuo en particular, el alcalde de Chaitén, quien como autoridad política de la zona podrá dar información diferente a la que entregarán los habitantes de Chaitén, ya que por su condición puede informar de cómo se veía este proceso desde las esferas del poder político, tanto de su propio municipio como del Gobierno.

Se realizaron finalmente 12 Entrevistas focalizadas semiestructuradas a habitantes de Chaitén entre los 29 y los 80 años, con una media de edad de 49 años, y de los cuales $42 \%$ fueron mujeres y $58 \%$ hombres. El $50 \%$ de los entrevistados nacieron en Chaitén, $75 \%$ en la misma región y $25 \%$ en otras localidades de Chile. Además, $40 \%$ del total de los participantes declararon ser hijos y/o nietos de los primeros habitantes del pueblo.

Entre los entrevistados se encuentran un funcionario municipal, un carabinero en retiro, la fundadora de la agrupación "Hijos y amigos de Chaitén", la presidenta de la Junta de vecinos "Chaitén Vive" y un ex concejal del pueblo.

Y como se indicaba otra entrevista con preguntas diferentes para quien fuera el alcalde de Chaitén en el momento de la realización del trabajo de campo.

Para el análisis de las entrevistas en profundidad se decidió optar por el análisis de contenido. Esto porque la investigación realizada pretendía ser una reconstrucción de la experiencia vivida por los habitantes de Chaitén y es por 
medio del análisis de contenido, más la recolección cronológica de los hechos ocurridos (mediante fuentes secundarias) que se podrá comprender de mejor manera cómo y por qué se articula un Movimiento Social de resistencia por parte de los chaiteninos.

En términos generales, el análisis de contenido cualitativo se caracteriza por ser una técnica que permite inferir resultados a partir de ciertos datos formulados por los entrevistados, ya que a partir de las temáticas a las que más recurren los individuos es posible determinar las significaciones y percepciones que poseen tanto de sí mismos como de los demás en el contexto social en el que se encuentran inmersos.

El modelo de análisis propuesto sigue un desarrollo de categorías deductivas, es decir, que a partir de la teoría antes explicitada se procedió a categorizar el material obtenido de las entrevistas.

La información obtenida de las entrevistas entonces, se analizó en base a los objetivos de la investigación, a partir de lo cual se construyeron algunas categorías temáticas que permitieran poder reconstruir temporalmente el proceso de articulación del movimiento social por la recuperación y reconstrucción del pueblo de Chaitén, y otras categorías temáticas que fueran transversales al proceso, a través de las cuales se pudiera dar cuenta del porque los chaiteninos deciden llevar a cabo esta lucha. También se estudió cómo fue visto todo este proceso desde parte de las autoridades, tanto locales como de gobierno.

Las categorías temáticas en las que se estructuró el análisis fueron las siguientes:

1. Proceso de evacuación y erradicación de los habitantes de Chaitén tras la erupción.

2. El regreso al pueblo de Chaitén y la articulación del Movimiento Social de resistencia por la recuperación y reconstrucción del pueblo.

3. La capacidad resiliente de los habitantes de Chaitén.

4. Prácticas organizacionales para la reconstrucción del pueblo.

5. Motivaciones tras la articulación del movimiento.

\section{RESULTADOS}

Las primeras formas de organización de los chaiteninos se llevaron a cabo en los poblados donde habían sido evacuados: Puerto Montt, Castro y Osorno.

Una de las primeras acciones organizadas para demostrar el disgusto con lo que estaba aconteciendo fue la primera protesta realizada en Puerto Montt por los chaiteninos.

El primer retorno momentáneo al pueblo comenzó a gestarse en el mes de julio de 2008, como expresaron los entrevistados, habiendo transcurrido 2 meses desde la erupción, y más que nada dicen, consistió en poder entrar todos los días un par de horas al pueblo en horario determinado a mirar cómo habían quedado sus cosas y ver qué recuerdos podrían rescatar, para luego por orden de la autoridad tener que ir a pernoctar a otro lugar. Se relata la existencia de un grupo de 12 personas que formaron parte de ese proceso.

Se habla además, de la formación de una organización por parte de los chaiteninos (Hijos y amigos de Chaitén), creada con anterioridad al regreso al pueblo (mientras estuvieron evacuados), hecho que les permitió posicionarse ante las autoridades como sujetos unidos dispuestos a dar una pelea para recuperar su derecho a estar en su pueblo.

El retorno más definitivo al pueblo se fue gestando a través de la estrategia de acercarse lo más posible a Chaitén, permaneciendo en éste el mayor tiempo posible y pernoctando en algún pueblo cercano. El Gobierno por su parte buscaba impedir que los "rebeldes" estuviesen mucho tiempo en el pueblo, para esto los hacía sentir como "delincuentes encarcelados", tal cual como expresaron se sintieron. Sólo podían entrar y salir de Chaitén en horarios determinados y siempre con el carnet en la mano.

Esta lucha tranquila y apaciguada tomó un giro en el momento en que algunos chaiteninos decidieron desacatar toda orden impuesta por la autoridad y volvieron a habitar su pueblo de manera "ilegal", tomándose sus propias viviendas hasta que lograsen ganar la batalla. Además, al mismo tiempo para proteger su derecho a habitar el pueblo, los chaiteninos establecieron un recurso de protección ante la justicia para tener libre circulación de entrar 
y salir de su pueblo cuando ellos quisieran, acción que la justicia les aprueba. Esto evidentemente les permitió ir volviendo a habitar Chaitén, hecho que puede ser visto como la primera batalla ganada por los "rebeldes" en esta guerra por recuperar sus derechos y regresar a su pueblo.

Esto desde la teoría se puede ver cómo una acción de reterritorialización del pueblo, lo que implica que la lucha se comienza a organizar y a efectuar desde el territorio mismo que está en disputa y ya no desde el "exilio".

Chaitén se fue volviendo un espacio de resistencia, sentándose entonces las bases de un proceso de movilización bastante particular en el país hasta el momento.

\section{Estrategias por parte del Gobierno para evitar la reconstrucción en Chaitén}

Poco a poco el Gobierno de Bachelet comenzó a articular ciertas estrategias que tenían como objetivo evitar el retorno definitivo de los chaiteninos a su pueblo, entre éstas se encontraban no reponer los servicios básicos como agua y luz, buscando evidentemente incomodar y hacer mucho más complejo habitar nuevamente el pueblo, dar declaraciones ante la prensa en que se expresara que el pueblo de Chaitén "ha muerto" como lo hizo el ministro del Interior de la época Edmundo Pérez Yoma en febrero de 2009, y también la idea de querer construir una nueva ciudad en el pueblo de Santa Bárbara como alternativa de reconstrucción para los chaiteninos.

\section{Estrategias de movilización \\ por parte de los chaiteninos}

Ante las acciones realizadas por el gobierno para evitar la reconstrucción en Chaitén, se hizo necesario entonces que los "rebeldes" para contrarrestarlas se fueran organizando de manera más estructurada creando así sus propias estrategias para lograr ganar la batalla. Los habitantes que volvieron a Chaitén fueron poco a poco tomando una posición más firme y más radical en su actuar, comenzando a articularse en un movimiento social con características propias. Su objetivo principal expresan era que los dejaran vivir tranquilamente en su pueblo y que les devolvieran los servicios básicos como la luz, el agua, la salud y la educación.

Los diferentes discursos fueron relatando los métodos de movilización que se utilizaron para lograr llamar la atención de las autoridades y también de los medios de comunicación, apelaban que al hacerse el tema público al Gobierno no le quedaría más opción que comenzar a negociar para encontrar posibles soluciones. Entre estas acciones de los chaiteninos, encontramos la toma y protesta en la rotonda del pueblo, la posterior toma del puente de la ciudad, la toma de la carretera al lado del cementerio, la velatón frente a la gobernación.

Para organizar estas diferentes acciones los "rebeldes" dicen haberse reunido en una junta de vecinos que formaron, la cual tenía como principal objetivo que Chaitén se reconstruyera en su lugar original de emplazamiento, en esta orgánica -expresan- se juntaban la mayoría y tomaban las decisiones respecto a cómo enfrentarían a las autoridades.

En esta junta de vecinos que formaron participaban los que querían y las decisiones -dicense tomaban votando a mano alzada, lo que da a conocer que la forma de participación que tenían los "rebeldes" era de carácter horizontal.

Sin embargo, estas estrategias tuvieron oposición por parte de las autoridades de gobierno, quienes en muchas ocasiones recurrieron a la fuerza pública (carabineros) para desarticular las movilizaciones, lo que provocó que en el territorio estallaran brotes de violencia que no eran comunes en la zona.

Todo esto hacía que el conflicto hubiese tomado para algunos el carácter de una "guerra" entre los habitantes que habían vuelto a Chaitén y las autoridades de ambos gobiernos, tanto de Bachelet y Piñera, que debieron enfrentarse al conflicto.

Una acción que marcó una diferencia probablemente fue el hecho de que el alcalde haya decidido venirse a vivir nuevamente al pueblo (enero de 2009), a pesar de la negativa del Gobierno. Esto demostraba en parte su apoyo a la lucha de los chaiteninos.

Como puede observarse la mayoría de las estrategias utilizadas por los "rebeldes" correspondieron a acciones colectivas de carácter no institucional, ya que ante las estrategias utilizadas por el Gobierno para evitar la reconstrucción del 
pueblo, los chaiteninos no tuvieron más opciones que recurrir a una vía de carácter más disruptiva, realizando entonces tomas, funas y manifestaciones en general. Esto se debió a que no existían los canales institucionales suficientes para poder llegar a una solución del conflicto con el gobierno.

Es finalmente en diciembre de 2010 que el Gobierno da su mano a torcer y comunica a través del Intendente regional, Juan Sebastián Montes, que Chaitén se reconstruirá finalmente en su lugar original de emplazamiento, pero sólo en el sector centro-norte de la ciudad. Todo esto implicaba que los servicios públicos (gobernación, educación, tribunales, notaría, banco, vialidad, entre otros), así como también los servicios básicos (luz, agua, salud) irían siendo restablecidos a la brevedad posible (Diario El Vacanudo, 2010).

El movimiento social de los chaiteninos fue siempre una orgánica pequeña (en sus momentos más álgidos no pasaron de ser mucho más de 30 personas activas en el movimiento), compuesta por individuos heterogéneos.

El conflicto tomó ribetes inesperados para ambas partes, por un lado los chaiteninos en ningún momento pensaron que el Gobierno les impediría rehabitar Chaitén durante un periodo tan largo de tiempo, ni que actuaría con medidas de violencia física, psicológica y económicas para evitar el reasentamiento de la población. Esto llevó a que los chaiteninos comenzaran a desconfiar profundamente del Gobierno ya que con medidas como las efectuadas se les hacía difícil ver cuáles eran sus verdaderas intenciones, el problema para ellos entonces dejaba de ser la erupción del volcán y sus consecuencias, el problema pasaba a ser el Gobierno y cómo enfrentarlo.

El Gobierno por su parte tampoco pensó en encontrar en los habitantes de este pueblo una fuerza, una resistencia y una capacidad de organización como la que desarrollaron.

Son estos hechos entonces, los que finalmente llevan a los chaiteninos a crear una red de interacción que tomará la forma de un movimiento social territorial con características particulares; características que lo hacen diferente del modelo tradicional de movimientos de este tipo que se presentan en la teoría.

Como se ha dicho en el marco conceptual, es necesario comprender cuál es el componente principal que hay tras la articulación de este movimiento.

\section{Agrupaciones chaiteninas}

Para reconstruir el pueblo se forman dos organizaciones por parte de los "rebeldes"; por un lado, la agrupación "Hijos y amigos de Chaitén", que se formó en Puerto Montt (mientras estaban evacuados) bajo el objetivo de poner una voz común para los chaiteninos a través de la cual pudieran hacer valer su derecho a regresar al pueblo, así como también para -una vez que estuvieron de vuelta- ayudar a chaiteninos que tenían problemas de recursos para el tema vivienda y alimentación, pero que a pesar de ello habían decidido volver al pueblo.

La otra organización relevante fue la Junta de vecinos "Chaitén Vive", que se forma bajo la consigna de demostrarles a las autoridades que Chaitén seguiría siendo habitado a pesar de su negativa. Además de ello, tenían como tarea organizarse entre todos para limpiar y arreglar el pueblo, y también juntar y entregar beneficios a quienes lo necesitaran.

\section{Motivaciones}

En cuanto al análisis de cuáles fueron las motivaciones que llevaron a los "rebeldes" de Chaitén a articular un movimiento social territorial, a través del cual pudieron luchar para recuperar, rehabitar y reconstruir su pueblo, se encontró lo siguiente:

\section{Factor filiación}

En sus relatos los chaiteninos se reconocen como descendientes de los primeros fundadores de Chaitén. El hecho de ser hijos o nietos de colonos los hace verse a ellos mismos como similares, provenientes de la misma herencia histórica, donde el sacrificio por sobrevivir era cotidiano.

Descender de estas familias fundadoras probablemente los hizo fuertes, resistentes y los ha hecho amar la tierra que han ido construyendo. Tener que haber vuelto a luchar para construir nuevamente su pueblo forma parte de su propia historia familiar.

A partir de esto, se vuelve evidente que en Chaitén hay un pasado histórico y una memoria 
colectiva que une a muchos de los individuos que decidieron regresar al pueblo. Se puede afirmar con mayor seguridad que se está en presencia de una cultura en común que los une.

\section{El arraigo a la tierra de Chaitén}

Las experiencias relatadas por los "rebeldes" respecto al arraigo a su territorio son bastante similares, los testimonios daban a conocer el fuerte amor que sienten por esta tierra, que ha sido trabajada y transformada por sus propias manos y la de sus ascendientes en la mayoría de los casos. Este arraigo los ha hecho volver a pelear por recuperar su pueblo, no importando si lo habían perdido todo o habían quedado con algo, y no importando tampoco cuáles fueran las condiciones en las que hubiese que sobrevivir, lo importante era mantenerse en su lugar, su tierra.

Se hace más evidente cómo el territorio de Chaitén parece ser un objeto de representación simbólica y de apego afectivo para la mayoría de los chaiteninos que regresaron, reflejado principalmente en el amor que expresaban cuando hablaban de su pueblo, tanto los que nacieron en este lugar, como aquellos que hicieron de este lugar su hogar.

Otro motivo que había tras las acciones de los "rebeldes", y que se refleja en sus discursos, es el particular arraigo que tienen al modo de vida que llevan en Chaitén, en contraste con el de una ciudad más grande, como las que habitaron mientras estuvieron evacuados (Puerto Montt, Osorno y Castro principalmente). Ven estas ciudades como lugares que representan una forma de vida que les es desagradable, donde todo está hecho de cemento, lleno de gente y donde hay que hacer filas para abastecerse de los productos básicos.

El arraigo a Chaitén se refleja acá en la comparación del tipo de vida que pueden tener en el pueblo a diferencia de la vida fuera de éste. La vida en Chaitén se describe como tranquila, menos compleja, como un lugar donde se puede sobrevivir mucho más fácilmente porque todo está ahí mismo y porque el dinero es menos necesario que en otras partes, pudiendo incluso ahorrar. Se agrega que es incluso un lugar más saludable para vivir, la vida es mucho más relajada dicen, ya que este modo de vida particular promueve una mejor salud mental.

Al adentrarse más específicamente en el tema de cómo los "rebeldes" caracterizan la vida en Chaitén mismo, dicen ver su pueblo como un lugar muy tranquilo, donde nadie se estresa, no existe la delincuencia y donde todos se conocen y comparten. Esto último se vincula directamente con la idea que en Chaitén hay una comunidad con características particulares en la que sus habitantes se sienten parte de un modo de vida que les otorga seguridad y confianza, lo que para ellos los hace tener una alta calidad de vida.

Se hacía mucho énfasis también en la naturaleza y en el tipo de paisaje que hay en Chaitén, dicen tener de todo en cuanto a clima y recursos naturales, los que son apreciados como bienes que le dan gran riqueza a la zona, y que se podría decir ya forman parte de la propia cultura de la región. Por un lado, estos recursos parecen darle un carácter único y propio al pueblo, y por otro lado, han sido también a lo largo de la historia de Chaitén los elementos que les han permitido a su población ir sobreviviendo.

\section{Características de los chaiteninos}

Este modo de vida particular que tienen los chaiteninos se refleja también en su identidad, es por ello que se hace relevante conocer cómo se caracterizan los habitantes de este pueblo. Los chaiteninos en los discursos se dan a conocer como personas que se sienten libres y que aman su tierra, y entre los valores típicos que los caracterizan y los hacen diferentes de los habitantes de otros lugares aparecen la solidaridad, la empatía, la cordialidad y la confianza.

En los discursos se da a conocer también la capacidad de aguante y resistencia que dicen tener los chaiteninos, esa capacidad de levantarse y de pelear por lo que creían justo, sobreponiéndose entonces a la catástrofe y dándose cuenta de los fuertes que podían llegar a ser estando unidos y organizados, a pesar de ser pocos.

Se relata que muchos chaiteninos cayeron en una depresión tras la catástrofe y necesitaron entonces ayuda psicológica, ésta les permitió el ir viviendo el duelo de la pérdida e ir aceptando poco a poco su situación. Pasado el tiempo fueron sobreponiéndose y comenzaron a buscar soluciones. Desde la teoría de la resiliencia esto es visto como el momento "basta ya", momento en el que se de- 
cide aceptar la situación y emprender un nuevo rumbo en el que se pretende ir reconstruyendo lo perdido, y en este caso eso puede reflejarse cuando algunos chaiteninos deciden dejar el lugar en el que estaban evacuados para volver nuevamente a su pueblo a reconstruir las vidas que habían dejado atrás, a pesar de lo difícil que saben sería para algunos comenzar de cero nuevamente.

A partir de la investigación se dilucidó que hay al menos tres razones principales que permiten explicar por qué los "rebeldes" deciden volver a su tierra a luchar por el derecho de habitarla nuevamente:

1. El arraigo a un modo de vida particular parece ser la razón más fuerte que movilizó a los "rebeldes" para llevar a cabo la pelea que dieron. Chaitén es para sus habitantes un lugar cómodo, agradable, muy tranquilo para vivir y donde la calidad de vida que pueden llegar a tener es más alta que la que tendrían en otras ciudades de Chile.

2. Las raíces familiares e historias de vida de muchos de los "rebeldes" están en Chaitén (muchos son hijos o nietos de los primeros colonos); el territorio es un espacio de sedimentación simbólico-cultural para ellos, es el soporte de sus identidades. Es por ello entonces que la vida del chaitenino adquiere mucho más sentido cuando está en la tierra que hace pocas generaciones viene construyendo.

3. El arraigo a la tierra de Chaitén, lo que se expresa en el fuerte apego afectivo que dicen sentir por su pueblo, en lo que se incluye también como agregado el sentimiento nacionalista por Chile que algunos chaiteninos expresan.

A partir de las características presentadas por los chaiteninos en sus discursos y de la identidad que tienen en común, es que se puede presumir que se sienten parte de una historia que los ha hecho más fuertes y los ha llevado a tener más capacidad de resistencia que otros pueblos de Chile, como un entrevistado afirmaba "ningún otro pueblo de Chile hubiese aguantado tanto como nosotros". Es probable que esta misma característica que les permitió a sus padres y a sus abuelos construir un pueblo en un lugar sumamente aislado y poder sobrevivir a ello, es la que han sacado a flote los "rebeldes" de Chaitén que han decidido regresar a reconstruir su pueblo.

Haberse levantado y comenzado casi de cero a reconstruir su pueblo es una característica que parece entonces inherente a los chaiteninos, se refleja en su autoestima colectiva y en su identidad cultural en común (ambos factores potenciadores de la resiliencia), lo que facilita poder considerarlos como un pueblo con alta capacidad resiliente.

Los "rebeldes", al regresar a su pueblo entonces, vuelven motivados no sólo por la idea de recuperar su tierra, su propiedad, sino también de continuar la historia que muchas de sus familias han construido en este lugar y continuar igualmente con un modo de ver y de hacer las cosas que es particular de esta zona. La identidad del chaitenino y su forma de vida sólo parece tener sentido en Chaitén.

\section{DISCUSIÓN Y CONCLUSIONES}

El proceso de formación de los nuevos movimientos sociales sigue siendo un fenómeno más bien reciente en la historia de la humanidad. A partir de los últimos 30 años se ha podido observar una explosión creciente de este tipo de agrupaciones, integradas por individuos que pertenecen generalmente a distintas posiciones dentro de la estructura de clases. La teoría social se ha visto en la necesidad de explicar cuáles son los componentes y formas de organización principales bajo los que se articulan los movimientos sociales hoy en día.

Esta investigación tuvo como objetivo dilucidar las motivaciones y prácticas que llevaron a algunos habitantes de Chaitén a articular un Movimiento Social de resistencia por la recuperación y reconstrucción de su pueblo en su lugar original de emplazamiento, tras la erupción volcánica que los afectó. Se utilizó una metodología cualitativa a partir de la cual se analizaron los discursos de los diferentes actores que formaron parte de este proceso, pudiendo identificar y conocer de esta manera las particularidades de esta forma de movilización.

Como resultado del análisis efectuado se 
puede decir que el movimiento social de Chaitén tiene como punto de inicio el momento en que los "rebeldes" dejan de reclamar y pelear por sus derechos ante las autoridades de manera individual -mientras estuvieron evacuados- para pasar a darse cuenta que si se organizaban para exigir sus demandas podrían lograr más fácilmente el objetivo de dejar atrás la desterritorialización obligatoria a la que estaban siendo sometidos, para volver entonces a territorializarse nuevamente en Chaitén. Tal cual como señala Mançano (2005), muchos movimientos socioterritoriales se forman a partir de estos procesos de territorialización y desterritorialización.

A partir de las dimensiones que plantea Svampa (2007) para caracterizar a los movimientos sociales latinoamericanos de las últimas décadas, el movimiento social formado por los "rebeldes" presentaba además del evidente anclaje territorial, las otras tres dimensiones, la acción directa no institucional que se expresaba en las manifestaciones, tomas y funas realizadas por el movimiento; la democracia directa como forma de tomar decisiones respecto a su accionar; y la autonomía expresada en la búsqueda de los chaiteninos de autodeterminarse como comunidad nuevamente en su tierra.

En cuanto a sus formas de expresión el movimiento -como se relataba- se caracterizó principalmente por realizar acciones de carácter disruptivo. De esta manera, buscaban dar a conocer su problemática y sus demandas, y así lograr comunicarse con el aparato gubernamental para negociar con éste una solución al conflicto. Sin embargo, cuanto más el Gobierno se negó a escuchar a los chaiteninos, más se fue estructurando y consolidando el movimiento formado por los "rebeldes". Tal como dice Melucci (1989), cuando hay un conflicto social la identidad colectiva del grupo afectado se intensificará y se producirán acciones de movilización, las que a su vez tenderán a acrecentar más la pertenencia de los individuos que forman parte del movimiento que se está gestando.

El componente particular de este movimiento, que permite diferenciarlo de otros movimientos socioterritoriales de la región, se expresa en la fuerte pertenencia y arraigo que los chaiteninos sienten por su tierra.
Este componente cultural fue analizado a partir de todo el relato construido sobre este pueblo durante la investigación, pero a modo de simplificar se mostrará cómo se refleja en los 3 tiempos históricos de Chaitén:

a) En el pasado del pueblo, como historia familiar y memoria colectiva que conecta a los habitantes que han regresado a Chaitén con la forma de vida de sus antepasados, los colonos.

b) En el presente del pueblo, como componente cultural que hace a los chaiteninos que regresaron sentirse parte de un grupo, de una comunidad pequeña que a través de la organización ha logrado estar hoy reconstruyendo su pueblo y la forma de vida que en éste llevaba.

c) En el futuro del pueblo, como objetivo común de volver a hacer de Chaitén el lugar que era hasta antes de la erupción.

Esta identidad cultural del chaitenino arraigada a un lugar, a una historia y a un modo de vida, no es más que la identidad cultural que poseían los colonos de esta tierra. Características como la tranquilidad, la libertad, la solidaridad, la armonía con el medio ambiente natural en el que están inmersos y la empatía, entre otras, son valores que se han mantenido a lo largo del tiempo en estos habitantes, pero otros como el sacrificio, la austeridad, la resistencia, fueron levemente minimizados por los beneficios que la modernidad produjo en este territorio, ya que evidentemente con el desarrollo que había alcanzado el pueblo de Chaitén -hasta antes de la erupción- la resolución de las necesidades y el acceso a ciertos bienes se habían facilitado, por lo que estos últimos valores habían dejado de tener el peso que tuvieron en los inicios de este pueblo.

Sin embargo, a partir de la erupción parecen haber resurgido mucho más fuertemente, siendo estos valores comunes los que le dan la fuerza a los "rebeldes" para llevar a cabo todo el proceso de lucha y resistencia que realizaron. Tener que regresar a reconstruir el pueblo, organizarse para esta tarea, ayudarse unos a otros a limpiar sus casas y lograr sobrevivir sin servicios básicos durante casi 3 años fue una tarea que, a pesar de lo complejo, 
les resultó bastante bien. Hecho que se puede explicar a partir de que las capacidades necesarias para llevar a cabo este proceso formaban parte de la herencia cultural transmitida por sus antepasados colonos.

Mientras estuvieron evacuados, los chaiteninos que más querían volver eran aquellos que tenían más arraigo y sentimiento de pertenencia hacia la tierra de Chaitén.

Este fuerte arraigo que sienten estos chaiteninos queda de manifiesto en la necesidad de revincularse nuevamente con su espacio geográfico y con un modo de vida que es único y particular de este lugar.

Todas estas características permiten explicar por qué algunos chaiteninos tienen un arraigo mucho más fuerte que otros para con esta tierra, lo que se expresa sobre todo en aquellos que han vivido bajo estos ideales desde que nacieron.

Respecto al rol que cumplieron los gobiernos que les tocó enfrentar el conflicto, en ningún momento hubo por parte de ellos una respuesta clara a las peticiones de los chaiteninos, más allá del haber estado ejerciendo violencia de manera continua sobre los habitantes del pueblo que habían regresado.

Esto marcó evidentemente a los chaiteninos ya que cambió la concepción que tenían sobre el Estado, pasando de la idea de un Estado "benefactor" que debe defender los derechos de sus ciudadanos y que los debe hacer sentir valorados y respetados, visión que fue inculcada a los chaiteninos (por sobre todo durante la dictadura militar de Pinochet) a través de la generación de un fuerte sentimiento nacionalista basado en la importancia que tenía esta zona fronteriza para Chile, a pasar a una concepción de un Estado que ha dejado de cumplir ese rol, haciendo sentir a los chaiteninos no sólo desprotegidos y poco valorados, sino que peor aún no respetando sus derechos y violentándolos; un Estado que se impone frente a sus ciudadanos.

El movimiento social de Chaitén amplía en este sentido el debate respecto a cuál debe ser el rol del Estado frente a las problemáticas territoriales, las que como se sabe siempre han existido en Chile desde su conquista y que aún se expresan hoy en conflictos ancestrales como el mapuche.

Surge la pregunta entonces: ¿Es el Estado el que debe decidir qué lugares pueden habitar sus ciudadanos o son los ciudadanos los que autónomamente deben decidir cuáles son los lugares en los que se quieren asentar?

En este sentido el movimiento social de Chaitén marca un hito, ya que logra hacer que la soberanía territorial -al menos por esta vezresidiera en el pueblo y no en los gobernantes.

Elegir en qué lugar vivir debe ser un derecho que resida en las personas, en los pueblos y no en el Estado una comunidad sólo se podrá desarrollar en los lugares que les hace sentido de vida, es por ello que la lógica local adquiere mucha relevancia a la hora de tomar las decisiones habitacionales.

Para los chaiteninos haber ganado esta batalla y haberse dado cuenta que compartían una historia, así como también valores y principios que marcaban una forma de vida particular, los lleva a sentirse más plenamente parte de una comunidad que se podría decir existía anteriormente pero que no se articulaba a modo de organización colectiva. La participación en el movimiento social juega un papel primordial a la hora de crear un sentido de comunidad y organización más fuerte en Chaitén.

Es entonces la alta capacidad de resiliencia de los chaiteninos más una identidad cultural muy ligada al sentimiento de pertenencia, lo que les permitió articularse en un movimiento socioterritorial que luchó continuamente para "levantar al pueblo de las cenizas", y así poder decir hoy, tal como expresa el nombre de la Junta de vecinos formada durante este proceso, "Chaitén Vive".

\section{BIBLIOGRAFÍA}

Basile, H. (2002). Ética y Resiliencia Comunitaria en Argentina. Jornadas de Ética en Psiquiatría infanto juvenil de la AAPI. Buenos Aires. Recuperado en: http://www. consultapsi.psygnos.net//descargararchivos/ETICA RESILIENCIA_COMUNITARIA.zip

Della Porta, D., \& Diani, M. (1999). Social Movements an Introduction. Oxford: Blackwell Publishers.

Di Silvestre, C. (1999) Apuntes de Apoyo a la Docencia I. La Metodología cualitativa: sus principios subyacentes. Curso de Métodos y Técnicas cualitativas I, Departamento de Sociología. Santiago: Universidad de Chile.

El Vacanudo, Diario Ciudadano. Recuperado de: http://www. elvacanudo.cl/admin/render/noticia/24282 
Mançano, B. (2005). Movimientos Socioterritoriales y Movimientos Socioespaciales: Contribución teórica para una lectura geográfica de los Movimientos Sociales. Revista del Observatorio Social de América Latina, 1(16), 273-283.

Melucci, A. (1989). Nomads of the present: Social Movements and individual needs in contemporary Society. London: Temple Univ. Pr.

Oslender, U. (2002). Espacio, Lugar y Movimientos Sociales: Hacia una Espacialidad de Resistencia. Revista Electrónica de Geografía y Ciencias Sociales, 6(115).

Seoane, J. (2003). Movimientos sociales y recursos naturales en América Latina: Resistencias al neoliberalismo y configuración de alternativas. Buenos Aires: CLACSO.

Seoane, J., Taddey, E., \& Algranati, C. (2004). El concepto movimiento social a la luz de los debates y la experiencia latinoamericana recientes. Buenos Aires: CLACSO.

Suárez, N. (2001). Resiliencia: Descubriendo las propias fortalezas. Buenos Aires: Paidos.

Svampa, M. (2006). Movimientos sociales y nuevo escenario regional: Las inflexiones del paradigma neoliberal en América Latina, Cuadernos del CISH, 19 (20), 141155. Buenos Aires: Universidad de La Plata.

Torres, O. (2011). Marco conceptual e Investigaciones realizadas sobre Resiliencia Social y Comunitaria. Conferencia Virtual Iberoamericana: La Cultura Preventiva como factor de Resiliencia frente a los Desastres. Madrid. Recuperado en: http://es.scribd. com/doc/262589413/Sesion-Tecnica-1\#scribd

Villarroel, G., Delgado, G., \& Jeldes, C. (2005). Chaitén: su historia desde la memoria. Santiago: Caminante libros. 